\title{
Exposure and sexual risk among young women in a Free Trade Zone in Sri Lanka
}

Tilak Hettiarachchy', Stephen L. Schensul'

The Ceylon Journal of Medical Science 2002; 45: 47-57

\begin{abstract}
This paper based on a two-year study of behaviour patterns of working women in Free Trade Zone (FTZ) at Katunayake, seeks to find out the level and social processes of sexually risky behaviour of these women so that risk reduction methods may be introduced. In this exercise a total of 1162 working women who had a rural background were surveyed with a very detailed questionnaire, generating 775 questionnaires that were sufficiently filled out to be considered complete for analysis. Most of the working women lived in boarding houses. For the great majority of women, their employment in the FTZ was their work outside the home. They worked long hours, walked home quickly and in groups for safety, cooked their meals and repeated the the same behaviour throughout the year. However a group of women with the earnings they made tried to enjoy life, getting involved with men in the FTZ communities. The data suggest that the opportunity for the development of relationships with men begin with a young woman affiliating with a group of women involved in risky sexual activities. The research identified three major domains, which. contributed to the risky sexual behaviour of working women. These are the residence, the family and work. Variations in these three domains make a girl more, or less exposed to sexually risky behaviour. Finally the paper identifies some corrective measures, which may reduce the sexually risky behaviour patterns of these women.
\end{abstract}

\section{Introduction}

Since the 1960s, there has been a rapid expansion in the global growth of "free trade zones" (FTZs).
Such zones have been created in developing countries as multinational corporations based in developing or newly industrialized countries, invested in labour intensive plants processing piece goods or raw material for export to European or US markets. FTZs have introduced a new category of workers - young women - into the industrial labour force. Women currently make up $40-80 \%$ of the labour force in FTZs in Southeast Asia, the Indian Oceana and Latin America. The great majority of workers in FTZs are young, unmarried women between the ages of $15-30^{\circ}$ years. These women are considered more suitable for FTZ work because they supplement household income rather than support households. Women were employed rather than men "as higher profits can be extracted from female labour due to low wages" (1).

Employment in most of the FTZs requires young women to leave their households and home communities, live in dormitories, and adapt to a life of hard work and long hours with little support from family. For many of these young women, entrance into the work force and associated communities represent their first experience away from the support and supervision of their family. The literature on women in the FTZ reports many examples of work-related physical, psychological, and emotional exploitation of young women $(2,3)$.

Developing countries, are highly ambivalent about young women working in FTZs. Though these provide employment opportunities to young women without much training or education yet the concept of an independent group of young, unmarried women with disposable income is perceived as a threat to the natural social order in such societies $(4,5)$.

\section{Professor, Department of Sociology, University of Colombo \\ 2. Department of Community Medicine, University of Connecticut School of Medicine, USA.}


Sri Lanka became involved in export processing in 1978 with the establishment of the FTZ in Katunayake, near the International Airport. It is now estimated that there are 60,000 workers in the Katunayake FTZ of which 52,000 are women; the greatest majority of which are young women between the ages of 16-25. The Katunayake FTZ has become a complex ecological niche comprised of factories behind high security walls and fences; dormitories, small buildings and family homes housing young women workers; shops and markets which, while providing basic food and living resources, emphasize jewellery, clothes and dresses geared for young women with disposable income; and large numbers of young and older men who loiter in the streets, of whom some derive their financial support by "living-off" the earning of young women (4).

Into this environment come young women drawn almost exclusively from the poorest sectors of rural communities (6). They are coming to communities which were traditionally focused on paddy cultivation and coconut plantations but with the development of the airport and the FTZ now includes industrial effluent, noise and air pollution, a saturated and polluted water table (5), overcrowding and other unhealthy environmental conditions. They work in factories that are crowded, poorly ventilated and have limited resources for the support of workers $(3,7)$. They live in crowded dormitories in which young women are living in very close physical contact using double-deck bunk beds for sleeping arrangements, two to a bed and many in a small room (8). Finally they must cope with continuous advances of men who congregate outside the factories, in bars, dark places and the deserted areas to lure, coerce, take advantage or violently prey on young women (4).

The popular media has characterized the lives of women workers in the FTZ as filled with stories of male manipulation, high rates of pregnancy, abortions, and abandonment. This paper is based on a two-year study of behaviour among FTZ women, which seeks to empirically determine the level of sexually risky behaviour in this population, to identify the social processes which can lead to risky sexual behaviour, and to use the re- sults as a basis for the development of effective risk-reduction programs.

\section{Sri Lanka: the national context}

Sri Lanka, which has a population of 18.6 million, is on par with developed countries in many indicators for quality of life such as life expectancy at birth, literacy, infant mortality, maternal mortality, and fertility and population growth rates (9). However the country fares badly in economic indicators with a low per capita income, a wide disparity in income distribution, a low economic growth rate, a high rate of inflation and unemployment, with a low labour force participation (10). Sri Lanka represents a positive outlier; a country in the bottom tiers economically and in the top tier in quality of life indicators. Observers of this phenomenon attribute Sri Lanka's performance to a commitment to a welfare state and a strong public health system since independence in $1948(10)$.

\section{Youth problems}

The mismatch between the education and employment has resulted in youth unrest in the country, both in the South and the North resulting in two civil wars and a separatist terrorist movement over the last two decades. With educational delays and unemployment, there has been a constant upward trend in the age of marriage among males and females that at present stands at 28 years for males and $26+$ for females. These delays have produced an "extended adolescence" which has created continued dependence on parents, inability to move from home, a lack of productive activity, pessimism and increased pre-marital sexual activity among youth (11).

\section{Sri Lankan FTZ development}

It is with the backdrop of these social issues that the development of the industrial sector in Sri Lanka can be understood. To encourage and attract foreign and direct investment, "free trade zones" were brought under a separate authority initially known as the Creater Colombo Economic Commission (GCEC), which made many concessions to foreign investors including a tacit communication that the current labour laws, which 
were nationally and internationally accepted, will be put in abeyance within the confines of these zones $(2,12,13)$.

The first of such export promotion zones was located near the Colombo International Airport and was better known as the FTZ at Katunayake. An area of 260 hectares was enclosed within high walls and a factory system was developed within $(4,13)$. Only the factory management, the Greater Colombo Economic Commission and workers had access to the factory complex. Very high production targets were set for workers who were punished by supervisors for failure to attain the production targets (8). Workers were not allowed to talk to each other and many factories worked around the clock on a shift basis. Work became particularly stressful when workers were enforced to do double shifts or overtime work to meet deadlines. Labour unions, which are well organized in the country, were discouraged within the FTZ and labour consultative committees that were established in their place were heavily biased towards the management (4). There is also a very high turnover of labour amounting to about $25 \%$ annually and over one-fifth of the required positions in the labour force are not filled despite high unemployment in the country:

The irony of FTZ development is that instead of employing unemployed males it virtually created a new labour force of young females who were not considered a part of the labour force in traditional Sri Lanka. This is reflected in the gender distribution of the FTZ in Katunayake where female to male ratio is 9:1 (7). This is also a device of keeping the wages low thereby increasing the profits of multinationals which attract more and more investments by them in the third world countries which are looking for more and more jobs $(14,15)$.

\section{The FTZ communities}

The FTZ factory complex was established in the middle of a suburban agricultural community, which was partly displaced by the expansion of the International Airport at Katunayake. As there was no forward planning for a large migratory labour force, the existing community residents started improvising, to meet the demand for resi- dential facilities made by the incoming workers. The community also attracted a new sector; outsiders who entered the area as service providers to the workers. They were involved in providing basic foods, transport, health care, laundry, tailoring, personal services such as hairdressing and also such luxury items as jewellery, cosmetics, shoes, garments and entertainment. Thus the community around the factory complex was transformed into a base for working women and the individuals who served their needs, and depended on their income.

To accommodate these workers, local residents transformed existing houses and built new structures to create congregate living for the incoming workforce. Most workers live in large boarding houses with almost 200 residents. The boarding houses can be both mixed or female only; in some there is a resident landlord, while others have no on-site person in charge of the premises. A boarding house could be a residential unit under one roof or it could be a conglomeration of housing units within a single estate, comparable to a slum community in an urban area. The construction and facilities provided in these boarding houses show wide differences ranging from wellbuilt, middle class houses to thatched roofed-huts similar to those in an agricultural community or urban slum community (7).

The most conspicuous aspects of this community are its youth and young adults (18-30 years), the extreme gender imbalance (females: male 9:1) and very close gender interaction seen every where unlike in the traditional community (4); young men and women are seen freely in each others company in the streets, in the bazaar and the shops, parks and everywhere, which is not normative in the Sri Lankan society. The attractive garments and accessories worn by the female workers is another aspect of this community that hardly misses the eye of the outsider.

\section{Risks to female workers}

The hard repetitive work for long hours aimed at attaining targets on time was physically and mentally exhausting to women workers. Tight on the job discipline which often restricted interaction 
with co-workers and the lack of contact with parents, other family members and friends from the village aggravated the situation further (5). Young women workers face a number of health risks caused by a variety of factors which include: poor nutrition due to lack of sufficient attention and resources for ensuring proper quantity and quality of food; various vector and waterborne illnesses caused by poor personal hygiene and an unhealthy environment; work related illnesses, such as headaches, respiratory illnesses, skin problems, and stress syndromes.

\section{Methods}

Data collection for this study was carried out using qualitative and quantitative methods. The first exploratory stage, involved interviewing key informants drawn from all categories of relevant people which included the factory managers, boarding house keepers, shopkeepers, transport providers, health service providers (belonging both to Western and traditional medicine), public sector officers from national and local administration, local police, religious organizations, NGO representatives in the area, and from the male partners of working women. Group discussions were held with public health midwives (PHMs), village officers (grama niladhari), three-wheel taxi drivers, female workers and female schoolteachers. Subsequently, systematic observations were carried out in the boarding houses, the streets, and the bazaars in which both physical aspects of these environments and the beinaviours of the males and females in these environments were observed and recorded in context. Such observations of behaviour patterns in their contextual settings provided valuable supplementary information and "triangulation" of information provided by key informants and group interviews.

The last step of the first stage of data collection involved all PHMs serving in the area, collecting information on specific cases of women workers who faced difficult situations in the community. Over a period of four months, case histories of forty working women who developed problem situations were collected.

The information collected in the exploratory stage of the study became the basis for the develop- ment of a quantitatively oriented questionnaire. The initial attempt to pilot the interview schedule was found to be unsuccessful because women were not comfortable talking about intimate behaviour. Therefore the interview schedule was changed into a self-administered questionnaire.

The final administration procedure for the questionnaire were carried out in the selected boarding houses where the sampled population filled anonymous questionnaires while the research team guaranteed the responses were individual and not collective.

\section{Sampling}

The research area was divided into three geographical units depending on the number of working women living in those areas. These three areas were categorized as heavy concentration area (adjacent to the factory complex), the medium concentration area (between a half to one and a half kilometers from the factory complex) and the low concentration area (between one and a half to three kilometers from the factory complex). All the main and peripheral roads and houses where workers lived were mapped. The boarding houses were enumerated and thirty $(30)$ were selected using stratified random sampling. The stratification was on the basis of the size of the boarding houses (small, medium and large) and the gender of the residents (mixed $v$ s. female only). Once the boarding houses were selected all residents present at the time of the visit of the research team were considered part of the sample. A total of 1162 women responded to the questionaire, generating 775 questionaires that were sufficiently filled to be considered complete. Analysis of the demographic characteristics of the questionaires that were only partially completed indicated no significant socio-demographic differences between those who had completed and not completed the questionnaires.

\section{Results}

\section{Demographic characteristics}

Almost all of the women in the questionaire sample belonged to the Sinhalese Buddhist ethnic

The Ceylon fournal of Medical Scicnee 
group and are from rural villages (98.2\%). The age of the women in the sample range from 16-38 years with a mean of $22.3 ; 97.1 \%$ are 30 years old or less and $52.1 \%$ are between 18 and 24 years of age. All were unmarried. The emphasis on education in Sri Lanka is evident in this population; $69.9 \%$ have had at least 6-10 years of education. However only a small number have passed their GCE O-Level exams (11\%), a basic requirement for lowlevel clerical positions, and an even smaller num-. ber have passed their A-Level exams (15\%), the basic requirement for a professional position. As relatively early school-leavers their options for employment outside the FTZ are limited.

\section{Families}

The women come from households in which fathers are predominantly small agriculturalists or agricultural workers, fishermen and labourers (71.2\%). They come from relatively large families, with a mean of 4.37 sibs considered high by Sri Lankan standards. They tend to be high in the birth order; close to $50 \%$ are either the first or second child, indicating added responsibility for supporting the family. Loss of father (17.8\%) and/ or loss of mother $(7.1 \%)$ seems to be $a$ factor in seeking employment in the FTZ. Over half the women $(52.1 \%)$ are working in the FTZ exclusively to support their families financially. Over half the women $(53.5 \%)$ see themselves returning to their parental villages when they leave their employment in the FTZ. There was a considerable range of variation in the degree of contact between parents and their daughter, working in the zone. For the past year, 37\% reported that they had no contact with their parents in the last twelve months. Most women made at least some financial contributions to their families $(64.2 \%)$ with $20.8 \%$ providing a small amount (Rs. $100-$ 500 ), $27.1 \%$ a moderate amount (Rs. 600-1000) and $13,9 \%$ providing a relatively large amount (over Rs. 1000) in the past year. Over a third of the women $(34.8 \%)$ made no financial contribution. Those women who cited support for family as the reason or one of the reasons they were working in the FTZ, provided significantly more financial contributions to the family than those women whose reasons were primarily personal.

\section{Residence}

Most of the women (79.6\%) lived in boarding houses or in smaller houses clustered on a single plot of land. A majority of women (55.5\%) lived in female-only housing. A significant number of women $(44.5 \%)$ were living with unrelated men under the same roof which is highly atypical for Sri Lankan circumstances. It should be noted that there is no male-only housing.

\section{Work}

For the majority of women $(84.6 \%)$, their employment in the FTZ was their first work outside the home. The mean length of employment and residence in the zone was 2.3 years for the women in the sample and the ethnographic reports indicate that most women stay for about a four-year period. A majority of the women maintained a bank account (57.6\%) and saved at least some money per month ( $84.6 \%$ ). The greater the amount saved, the more likely women were to maintain a bank account ( $p<.001)$. It is interesting to note that those women who saved some money monthly were less likely to send greater amounts of money to their families ( $\mathrm{P}=.031$ ).

\section{Peer relationships}

$$
\text { : }
$$

The majority of women work long hours, walked home quickly in groups for safety, cooked their meals in the limited space of their rooms and went to bed, repeating the same schedule on the following day. A subset of women, however, seek and maintain active relationships with their female and male peers that involves shopping, entertainment and activities outside the factory and their residences. From the questionnaire sample, $29.5 \%$ of the women report having female friends, frequently who have been in the FTZ for a longer period of time, who are involved in risky behaviours (alcohol use, living with a man, having sexual relationships). These friendships are formed within the factory and in the residence and provide young women the knowledge, the motivation, and the initial feeling of security to begin to involve themselves in the FTZ communities. 
Among the women in the questionnaire sample, $25 \%$ report having a "boyfriend." The concept of a boyfriend is not a feature of traditional Sri Lankan culture. The concept of a boyfriend is that young, unmarried women independently choose a man outside of parental approval, and can be with that man alone without supervision, and can participate in activities with that individual, which is not at all a part of accepted social norms in Sri Lanka.

The men in the FTZ communities with whom the women become involved are for the most part not permanent residents. They can include male workers in the factories, members of the armed forces stationed at Katunayake to guard the International Airport, men who have moved to the zone with other women to avoid problems in their home communities, and tradesmen and taxi drivers who serve FTZ communities but live with their wives and families in Colombo. These men may be married or unmarried but the case histories collected by the research team indicate that most of these men are more than willing to profess love and long-term commitment in return for a sexual relationship. With none of the familial, social or cultural constraints present in the FIZ communities as they would be in the rural villages, these men are free to conduct a sexual relationship and then move on to other women in the FTZ communities or disappear altogether.

One of the major contributing factors to a lost relationship is the announcement of the news to the boyfriend that the woman is pregnant. In many cases this is cause for the man to move from the community or find another relationship. Since few of the women $(31 \%)$ know about family planning and there was little report of the use of contraceptive methods (11\%) it stands to reason that pre-marital pregnancy is a distinct possibility in the "boyfriend" situation.

The qualitative data suggest that the opportunity for the development of relationships with men begin with a young woman affiliating with groups of women involved in risky activities. The quantitative questionnaire data affirms that there is a significant relationship between women friends involved in risky behaviours and having a boyfriend $(p<.001)$.

As one indicator of involvement in the world outside the dormitory and the workplace, $29.8 \%$ of women report attending musical evenings (music and dancing with large numbers of young men and women attending). Both having women friends involved in risky behaviours $(p<.001)$ and having a boyfriend ( $p<.001)$, are significantly related to attending musical evenings.

\section{An analytical model}

The second objective of the paper was to examine the social processes that contributed to risky sexual behaviour. On the basis of the qualitative data and the descriptive statistics derived from the questionnaire data, the following model is developed.

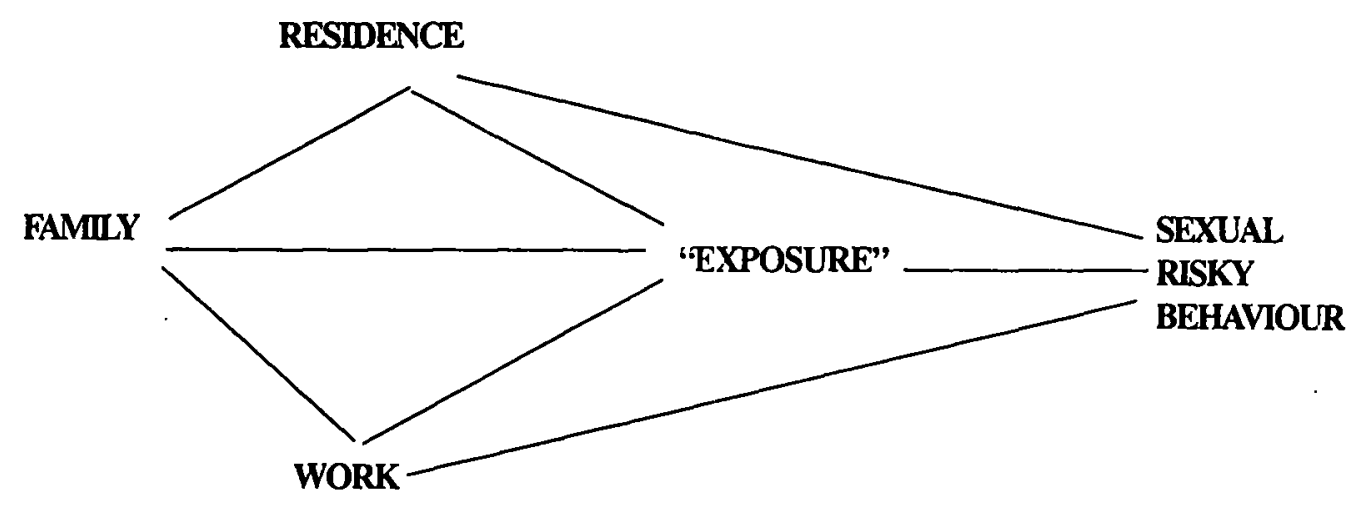

Figure 1. Analytical model

The Ceylon Journal of Medical Science 
The heart of this analytical model is the modifying factor we have labelled "exposure". This factor, comprised of "female friends involved in risky behaviours" and "having a boyfriend" differentiates those women who are involved in a life beyond their residence and their work from those who have no such life. As women become involved in these outside activities and link through their female and male friends, they "expose" themselves to the dangers of the FTZ community environment and the men in the FTZ communities. This exposure, it is hypothesized, significantly increases their involvement in risky sexual behaviour and its consequences.

This model futher argues that the three independent factors in a woman's life, her family situation (ongoing despite a range of contacts), the nature of her residence in the FTZ, and her work situation will be associated with her relative exposure. This model will be tested with a two-stage analysis using logistic regression. In the first stage the component variables that make up the domains of "family", "residence" and "work" will be examined as they relate to relative exposure. Then the variables within relative exposure will be examined as they relate to sexually risky behaviour.

\section{Independent variables associated with "exposure"}

For the purposes of binary logistic regression, the variable "exposure" was defined as consisting of two groups: either or both having "friends involved in risky behaviours" and "a boyfriend $(44.3 \%)$ vs. having neither (55.7\%). Variables from each of the three independent domains (family, residence, work) that were significant in bi-variate analysis (chi-square) were included in the equation. The results are shown in Table 1.

Table 1

Independent variables associated with exposure

\begin{tabular}{|l|c|c|c|}
\hline Variable & Odds ratio & S.E. & Sig. \\
\hline Work domain & & & \\
Do you save monthly & 2.921 & 0.430 & 0.013 \\
Having a bank account & 1.275 & 0.245 & 0.322 \\
Length of stay in FTZ & 1.122 & 0.224 & 0.606 \\
\hline Family domain & & &. \\
Woman visits home & 1.666 & 0.213 & 0.016 \\
Works to support family & 1.297 & 0.205 & 0.205 \\
\hline Residence domain & & & 0.205 \\
Mixed/Female only & 1.649 & 0.871 & 0.015 \\
Constant & 0.054 & & \\
\hline
\end{tabular}


The results show that there is a single variable in each of the three domains that significantly increases the odds of a woman being involved in relatively greater exposure.

- In the work domain the variable is whether the woman saves a part of her income on a monthly basis. As we have seen earlier, women who save money are less likely to remit a portion of their income to the family. In their case, women who save are close to three times as likely to have the finances to be involved in greater exposure.

- In the family domain the variable is whether a woman visited her parental home in the course of a year. Somewhat counter-intuitively, women who have visited their home at least once in a year are 1.6 times more likely to show greater exposure.

- In the residence domain the variable is whether the woman lives in a residence with women only or one which has both males and females. These women who live in a mixed gender residence are 1.6 times more likely to show greater exposure.

\section{Variables predictive of sexually risky behaviour}

The next step in the analysis is to include in the logistic regression equation the variables of exposure (having friends involved in risky behaviours and having a boyfriend) along with three variables associated with exposure (gender mix of residents, visits to parental home and saving money each month). The results are shown in Table 2.

Table 2

Variables associated with sexually risky behaviour

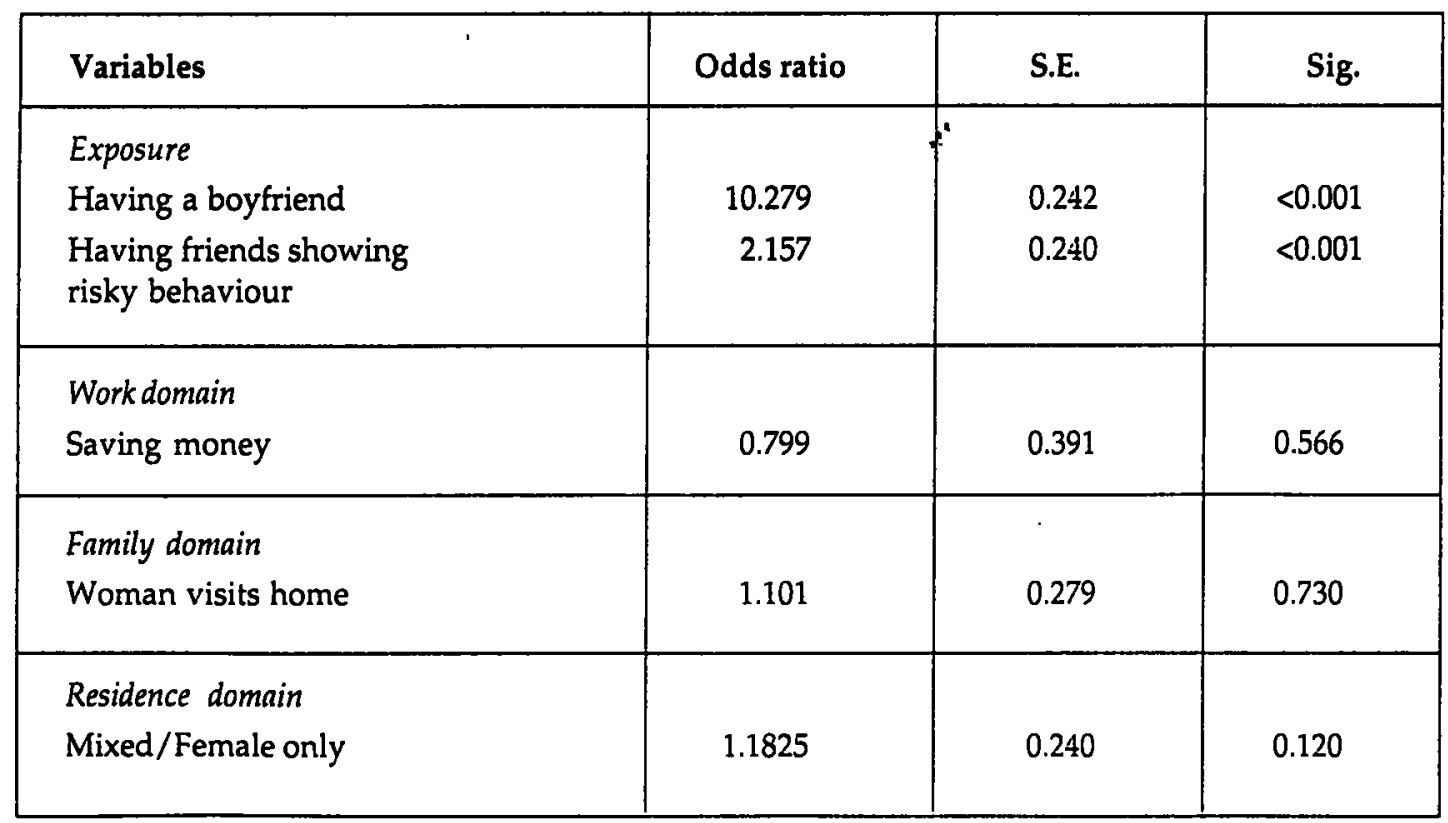

S.E. $=$ Standard error 
The results of this logistic regression show that three variables are associated with membership in the group involved in risky sexual behaviour.

- Having a boyfriend makes a woman to be 10 times more likely to be involved in risky behaviour. Since these women rarely engage in casual sex or have sex simultaneously with multiple partners, it takes a significant relationship with a man to create the context for a sexual relationship. Having a boyfriend in the FTZ is that context; unfortunately it rarely is predictive of a long-term relationship.

- Having female friends involved in risky behaviour doubles the odds that women will be involved in risky sexual behaviour. These female friends play a facilitative role in increasing the likelihood that women will meet men in the context of the FTZ communities.

- Living in a mixed gender residence in the FTZ makes a woman 1.8 times more likely to be involved in risky sexual behaviour than their counterparts in a female-only residence. Mixed gender residences not only include men who can be potential boyfriends, but also couples living together in a separate roqm. These couples may provide a model to a young woman coping with the loneliness and social isolation of the FTZ community.

The variables of visiting parental home and saving money on a monthly basis showed no significance when controlled for the three significant variables above.

\section{Discussion}

Young women are coming to the FTZ directly from traditional rural communities. A significant proportion come from households in which a parent is not in the household due to economic migration, death or separation/divorce or a parent is dysfunctional. due to alcohol or other problems. Their motivation for seeking work in the FTZ may be to support a not-fully functional family or to remove themselves from a difficult and oppressive situation. They come to a work and living situation, unlike any in Sri Lanka, in which there is a predominance of young women, an economy transformed from agricultural to one based on serving FTZ workers, and to an overcrowded and polluted environment. Having never lived away from home, they are forced to move into overcrowded, congregate housing with strangers, with a significant number of women living with strange men. They find a community in which all the cultural guidelines they have learned are not operative and they have no elders or relatives to assist in behavioural guidance. It is a community that is now attracting non-FTZ workers who seek one of the few locations in Sri Lanka where people can live outside traditional and community-imposed guidelines. They walk to the factories where work is long, repetitive and arduous and walk back home to a limited dinner in the constrained circumstances of their rooms. Most women visit home and their relatives visit them, but these visits are but short interruptions from a six to seven day week, 12 months a year work schedule with no paid holidays.

For a sub-population of women (44.3\%) this life is not sufficient and they begin to supplement their work and residential schedule with shopping, movies, musical evenings and other activities available in the FTZ community that are not available in their villages. Female friends facilitate this behaviour because the FTZ communities are too dangerous to walk alone, particularly at night. They meet a variety of men at work, in their mixed residences, in their walks in the community and at events and develop relationships. For most of these women $(69.4 \%)$, these relationships do not become sexual, despite the efforts of men who lack cultural and community constraints. It is only a minority from this group (30.6\%) that becomes involved in risky sexual behaviour. Since contraceptives are rarely used in these relationships $(69 \%$ said they knew nothing about family planning and only $11 \%$ were aware of condoms), women have a significant probabilty of unwanted pregnancies leading to an abortion or the difficult life of a single mother in Sri Lanka. Such consequences 
which most women indicated they wanted to return. As women leave the FTZ after a period of 4-5 years, there are many more rural women to replace them and continue the same cycle.

\section{Implications for action}

The final objective in this paper is to use the results and the methodologies used to engage women in the research process to outline a course of action that could assist young women in their adaptation to life in the FTZ and its environment. The elements of this action plan include the following:

Outreach to dormitories: The best location for engaging women under the present circumstances is at the dormitory residences.

Public Health Midwives (PHMs): They can be vital means of entry, obtaining information, and identification of problems and participants. Their ability for above activities could be enhanced by training.

Identifying change agents: The project would seek to hire young women of the same age cohort as the workers, who have had experience living and working in the FTZ as change agents.

Organize cooperative action in the dormitories: Observation of women in the dormitories has indicated that much could be achieved in improving their life situations by organizing cooperative action among the workers for which they could be given relevant training.

Legal and political advocacy: University, faculty and advanced students can provide training on rights of workers and residents.

Development of dormitory-based mobile health clinics: The PHMs will visit the dormitories on a monthly basis to examine women with health problems and refer them to the regular health care delivery system.

Reproductive health program: As the women workers have poor knowledge of reproductive health, a program would utilize the PHMs, the change agents and family planning agencies to provide education on reproductive matters including knowledge on contraceptives.

Counselling: Counselling on all aspects of life should be easily made available to the female workers.

Support systems for pregnant women: In order to prevent suicide, infanticide, abortion and a whole lot of other connected problems a support system for pregnant women should be established.

FTZs are a major phenomenon in our global economy. Their basic structure and function shows similarities across national systems and regions. Systematic research on the effects of FTZs on women is still inadequate as are models for effective prevention and education intervention programs. However the commonalities among FTZs suggest that generation of knowledge and mechanisms of intervention can have a positive effect not only locally but to FTZs anywhere in the world.

\section{References}

1. Forbel J,. Heinrichs J., Kreys $\mathrm{O}$. The New International Division of Labour, Cambridge University Press, 1980.

2. Lim L. Women workers in the multinational corporations: The case of electronics industry. in Malaysia and Singapore. Michigan Occasional Paper No. ix, Women's Studies Programme. 1978.

3. Grossman R. Women's place in the integrated circuit: Changing role of South East Asian women. South East Asian Chronicle No. 66, 1978.

4. Hettiarachchy T. Working in the Zone. Asian Human Rights Commission, Kowloon, Hong Kong, 1992.

5. Hettiarachchy T., Schensul S.L. The risks of pregnancy and the consequences among young unmarried women working in a Free Trade Zone in Sri Lanka. Asia -Pacific Population Journal 2001; 16: 126-140. 
6. Pearson R., Elson D. Internationalization of capital and its implications for the women in the Third World, Paper presented at the Institute of Development Studies, University of Sussex, England, 1978.

7. Report on the boarding/lodging houses around KEPZ 1989, Area administration development, Greater Colombo Economic Commission, 1989.

8. Women workers in the Free Trade Zone in Sri Lanka; A Survey. Voice of Women, 1983: 1.

9. National Human Development Report, Colombo. 1998.

10. Annual Report of Central Bank of Sri Lanka. 1998.
11. De Silva I. Ahead of target: Achievement of replacement level fertility in Sri Lanka before the year 2000. Asia Pacific Population Journal 2000; 9: 4.

12. Women and Wage Labour, News Letter, International Labour Studies No. 7, July 1980.

13. Safa H.I. The sex division of labour, development and women's status. Export processing and female employment, The Search for Cheap Labour, New York, 1980.

14. Helleiner G.K. Manufactured exports from less developed countries and multinational firms, Economic Journal, March 1973.

15. Trajtenberg R., Sajhan J.P. World Employment Programme Research. Geneva, 1976. 